\title{
¿SUPONE EL DERECHO UNIFORME UNA AMENAZA FRENTE AL DERECHO INTERNO? ¿PODRÍAMOS HABLAR DE UNA GUERRA ANUNCIADA?*
}

\author{
José Luis Marín Fuentes \\ Profesor de Derecho Internacional Privado \\ Facultad de Derecho. Universidad de Medellín (Colombia) \\ jlmarino@gmail.com
}

\begin{abstract}
RESUMEN
El presente artículo busca en cierta medida abordar la problemática que se presenta en muchos ordenamientos jurídicos con la aplicación a una situación jurídica dada de dos o más normativas que en su momento se presentan como idóneas para resolverla, pero donde una de ellas, en consideración a su jerarquía normativa, deberá ser aplicada de manera prioritaria frente a las demás. Todo esto genera ciertas dificultades entre los operadores jurídicos, quienes deberán sortear aquel conflicto para evitar un perjuicio a las partes implicadas. En este corto estudio se podrá observar que un ordenamiento jurídico actual y en el marco de la globalización, en especial la jurídica, no puede permitirse el «lujo» de funcionar solo con su Derecho interno de origen local, por esos se hace necesario que se le inyecte o aporte al mismo normas de carácter global que lo oxigenen y le permitan insertarse en el movimiento unificador global donde la armonía jurídica se sobreponga sobre los diferentes conflictos que a nivel interno se puedan presentar.
\end{abstract}

Palabras clave: Derecho uniforme, conflicto de leyes, armonización, tráfico privado, calificaciones.

\section{ABSTRACT}

The current article somehow seeks to approach the problem many legal systems have with double regulation which might apply to a given case where even if both seem to be possible one of them is thought to be primarily binding; all of the above raises controversy in between legal systems, who should skip such conflict in order to avoid damage to the parties. By looking into this short study we will be able to see that a current globalized legal system, namely the legal one, cannot afford working merely within the frame of its local law. It is therefore mandatory to be injected with global laws to cheer it up and which will allow it to become a part of

* El presente trabajo sigue la línea de otro que llevé a cabo titulado: «Derecho uniforme versus Derecho interno: ¿una guerra anunciada?», el cual expuse brevemente en un blog personal en el 2016 y que estimo no impide la eventual publicación del mismo. 
a global uniting movement where legal harmony prevails over the many conflicts that might appear on a local scale.

Keywords: united laws, collision of laws, Harmony and balance, private traffic. Qualifications.

\section{ZUSSAMENFASSUNG}

Der vorliegende Artikel sucht in gewisser Weise die Problematik zu erfassen, die sich in vielen Rechtsordnungen durch die Anwendung einer Rechtssituation ergibt, die auf zwei oder mebreren Rechtsnormen fußt, welche zu ibrer Zeit als geeignet angesehen wurden, um eine Rechtssituation zu lösen. Jedoch ist eine davon wegen ibrem normativen Rang als vorrangig gegenüber der anderen anzuseben. Dies erzeugt nun gewisse Schwierigkeiten bei den juristischen Akteuren, welche diesen Rechtskonflikt auflösen müssen, um Schaden von den Beteiligten abzuwenden. In dieser kurzen Studie wird aufgezeigt, dass eine aktuelle Rechtsordnung, im Rabmen der Globalisierung - besonders der juristischen - es sich nicht erlauben kann, nur aus innerstaatlichem Recht lokalen Ursprungs heraus zu funktionieren. Vielmebr ist es notwendig, dass dem innerstaatlichen Recht Rechtsnormen globalen Charakters beigefügt werden, um es zu «durchlüften» und es dadurch dieser lokalen Rechtsordnung möglich wird, sich in die Bewegung des globalen Gesetzeszusammenhangs einzuordnen, wo die Harmonisierung der Gesetze die verschiedenen Konflikte auszuschalten vermag, die sich dem innerstaatlichen Gesetz sonst stellen.

Schlüsselwörter: Einheitsrecht. Rechtskonflikt. Harmonisierung. Privatverkehr. Einstufung.

SUMARIO: I. INTRODUCCIÓN.-1. Consideración inicial.-2. Orígenes del Derecho uniforme.-3. El procedimiento de la unificación normativa.-4. Creación del Derecho uniforme.-5. Organismos creadores de Derecho uniforme.-6. Interpretación del Derecho uniforme.-7. Características del Derecho uniforme.-8. Incorporación del Derecho uniforme en el Derecho interno.II. PROBLEMAS DE LA INCORPORACIÓN DEL DERECHO UNIFORME.-1. El Derecho uniforme y las calificaciones.-2. El Derecho uniforme y el conflicto de leyes.-3. El Derecho uniforme y el forum shopping.-III. CONSIDERACIONES FINALES.-IV. BIBLIOGRAFÍA.

\section{INTRODUCCIÓN}

La aplicación del denominado Derecho uniforme puede conllevar que se presenten conflictos con el Derecho interno de un Estado determinado cuando se trata de darle solución a una situación jurídica planteada. Demostrar lo anterior solo será posible si se lleva a cabo un análisis, así sea somero, que nos permita inferir que tales conflictos efectivamente sí se presentan, y que pueden causar determinados traumatismos en cuanto a la solución de un litigio dado. 
Para lo anterior es factible que se considere necesario partir al menos de ciertos interrogantes que nos lleven directamente al núcleo del asunto. Estos se pueden resumir en las siguientes dos cuestiones: ¿puede la incorporación del Derecho uniforme en un determinado ordenamiento jurídico causar problemas en cuanto a la aplicación de su Derecho interno? e, igualmente, ¿es factible armonizar dos sistemas jurídicos que aparentemente son excluyentes en cuanto a su aplicación?

En la situación aquí planteada, sabemos de antemano que no es fácil luchar contra aquellos obstáculos que normalmente se presentan cuando de la aplicación de leyes o normas desconocidas (extranjeras) se trata, ya que en muchos casos se piensa que lo que ha sido creado por los legisladores responde a la voluntad del pueblo, y aquellos, como representantes del deseo popular, han tenido y tienen el conocimiento suficiente para crear normas que regulen situaciones propias, por lo que se hace irrelevante recurrir a normativas foráneas que no tienen ningún vínculo con la realidad que se vive dentro de ese ordenamiento jurídico.

Por ello, cuando se opta por vivir en un ambiente o sistema por así llamarlo de «autarquía jurídica» puede parecer normal el hecho de que sea innecesario acudir a normas extrafronteras para regular situaciones que no han tenido ningún contacto con el exterior. La consideración anterior pudo haber tenido cabida en épocas tales como lo fueron la Alta y la Baja Edad Media, donde el contacto con el exterior era mínimo, pero en la actualidad, esto es, en la era de la globalización, todo ello ha perdido su razón de ser. Por eso cuando un Estado o un individuo, llámese persona o empresa, quieren tener relaciones de cualquier tipo con sus homólogos en el exterior tendrán que «pagar» un precio, el cual variará de acuerdo con el valor que represente para él o ellos la obtención de ese beneficio proveniente de dicha relación y que la mayoría de las veces implica desprenderse de un porcentaje de su soberanía, a menos que lo que busquen sea imponer a los otros su voluntad sin pagar nada a cambio y recibir todo a su favor.

De ahí que el propósito del presente ejercicio sea esencialmente el de poner en evidencia el manejo que se le está dando actualmente al Derecho uniforme en diferentes ordenamientos jurídicos, donde, a pesar de existir como parte integral de los mismos, aún existen reticencias en cuanto a su aplicación, no se sabe si es por una cuestión cultural de rechazo hacia algo que no ha sido producido localmente o por cuestiones meramente de caprichos personales por parte de los diferentes operadores jurídicos, que tienen la función o la obligación de dar aplicación a ese Derecho uniforme o mal llamado extrafronteras. 
Con tal intención se pretende abordar en un primer lugar, y de forma muy tangencial, lo que se entiende por Derecho uniforme, sus orígenes, características e instituciones que lo crean, para luego confrontar su aplicabilidad en un ordenamiento jurídico dado y de esa forma mostrar si se cumplen los presupuestos de las preguntas que acarrea el presente trabajo y la utilidad o no del mismo en la comprensión de dicha temática.

\section{Consideración inicial}

En un primer lugar, con el fin de delimitar el tema que se va a desarrollar y desde un punto de vista muy general y abstracto, podemos señalar, entre otras cuestiones, que:

a) El Derecho como ciencia social o disciplina busca regular y entender los comportamientos de los seres humanos y se basa en una serie de normas y principios cuya idea esencial es la justicia y el orden en una sociedad o comunidad dada. A su vez, puede ser entendido como una norma de convivencia social, lo que implica que la sociedad, en general, para poder conseguir una convivencia pacífica necesita de unas pautas, reglas o normas de comportamiento que vendrán determinas por el sistema político que en cada etapa de la historia social exista ${ }^{1}$.

b) La autarquía es una forma de autosuficiencia en un sistema esencialmente económico donde las comunidades producen sus propios alimentos y satisfacen sus necesidades básicas con aquello que producen y en cierta medida se encierran en sí mismas evitando cualquier contacto con el exterior y definiendo su propia forma de vida.

c) La autonomía en el sentido político y social del término esencialmente determina una forma de independencia en cuanto a la toma de decisiones que tienen los seres; en otras palabras, es la capacidad de los sujetos de Derecho para establecer reglas de conducta para sí mismos y en sus relaciones con los demás dentro de los límites que la ley señala².

${ }^{1}$ M. Fernández Baquero, «Historia y fuentes del Derecho romano», disponible en http://digibug.ugr.es/bitstream/10481/21703/1/Historia\%20y\%20fuentes\%20del\%20derecho\%20romano.pdf.

2 Diccionario de la Real Academia de la Lengua Española. 
La razón de mencionar los términos anteriores es que estos nos pueden servir para entender, en primer lugar, aquellos sistemas sociales cuyo ordenamiento jurídico ha sido establecido esencialmente para regular de manera bastante particular, por no decir aislada, las relaciones entre sus propios habitantes, sin que se presenten influencias por parte de algún otro sistema normativo exterior donde el nivel de relaciones con los demás Estados es muy bajo.

En este caso, un interrogante que puede surgir frente a la descripción anterior es: ¿en la actualidad los Estados pueden sobrevivir en un sistema como el aquí descrito, es decir, aislados de los demás y con poco contacto con sus pares en el exterior?

Creemos que en tiempos de la globalización lo aquí descrito es visto quizá como una utopía, ya que, salvo algunas excepciones (Corea del Norte), cada día es más evidente la interrelación entre los Estados y sus sistemas sociales, económicos y jurídicos, lo que hace poco probable ver que haya un retroceso en cuanto a la correspondencia cada vez más amplia entre los miembros de la comunidad internacional.

Sin embargo, la realidad nunca ha sido esa, ya que, al parecer, desde los primeros tiempos existieron sociedades cuya forma de vida y desarrollo estuvieron enmarcadas en dicho sistema; de ahí que hallar el origen de esta clase de situaciones no es cosa fácil, toda vez que encontrar un antecedente exacto de cuándo sucede un hech o determinado en la historia es bastante difícil y se tiene además como pretencioso, al menos en lo que respecta a ciertos periodos de la humanidad.

Actualmente, con la tecnología y la inmediatez de la información es más fácil dar fe de ello, pero hasta hace poco era bastante o quizá más difícil llevar a cabo dicha tarea. Por esto, y a menos que sea una cuestión revolucionaria, la mayor parte del conocimiento que hoy poseemos ha sido el producto de una evolución histórica que, en el caso de las ciencias sociales, ha acompañado al hombre casi desde sus inicios hasta el día de hoy; en esto no podemos olvidar que en el devenir de la humanidad no ha sido una excepción la regulación de sus comportamientos en tanto que comunidad social y políticamente organizada.

En un sistema cerrado no es necesario que la comunidad acuda a normas producidas fuera de sus fronteras para regular comportamientos sociales en su territorio, ya que las que posee se presentan como suficientes para lograr tales propósitos. Un ejemplo de ello lo podemos encontrar en el llamado sistema feudal, donde no era necesario depender de los demás para sobrevivir. En efecto, cada feudo organizaba su propio sistema 
jurídico y regulaba sus relaciones de acuerdo al nivel de preparación del señor feudal, quien fungía como legislador, juez y policía. En este sentido es apropiado traer a colación lo expresado por Calicles (personaje principal del Gorgias de Platón), quien, como buen sofista y frente a una justicia entendida como ley no escrita o armonía natural, defendía el derecho de los más fuertes a tener un poder sin límites, pues ellos eran quienes hacían e imponían las leyes³.

Como vemos, las regulaciones jurídicas del tipo autárquico tuvieron alguna vez en la historia de la humanidad su momento y relevancia, pero el deseo de los hombres de relacionarse más allá de esas «murallas» hizo necesario que se acudiese a otro sistema más abierto donde, partiendo de la integración con sus congéneres, los individuos y los Estados, de una manera no tan autónoma, reglamentaron la vida en el interior de sus comunidades con unos elementos o normas similares que también eran aplicables a otras sociedades y podían de alguna forma dar solución a los mismos conflictos, aunque se presentasen en lugares diferentes; todo ello debido a que uno de los propósitos de la unificación de las normas es, básicamente, regular comportamientos análogos entre humanos sin importar las diferencias culturales o geográficas, ya que la interrelación personal es bastante idéntica debido que, en materia de evolución, la biológica es muchísimo más lenta que la cultural.

\section{Orígenes del Derecho uniforme}

Siguiendo esa búsqueda que nos ocupa, y de alguna manera un tanto aproximada, podemos señalar que el ius gentium es quizá la primera expresión de lo que por Derecho uniforme se puede entender, toda vez que como regulación especial debía aplicarse a las colonias del imperio, en cuyo caso cumplía una labor esencialmente de centralización de normas que eran idóneas para tratar situaciones jurídicas en diferentes lugares y bajo unos mismos parámetros previamente establecidos por el ius commune (visto este como un conjunto de instituciones jurídicas aplicable a todos los pueblos) ${ }^{4}$.

3 J. M. Ayala MarTíneZ, «El Derecho natural antiguo y medieval», Revista Española de Filosofía Medieval, núm. 10 (2003), pp. 378-396, disponible en bttps://www.uco.es/filosofiamedieval/sites/default/files/revistas/vol10/refmvol10a35.pdf.

${ }^{4} \mathrm{~J}$. AdAme GODARD, Estudios sobre la compraventa internacional de mercaderías, México DF, Universidad Nacional Autónoma de México, 1991, p. 170. 
En esa línea, Herrera indica al mencionar a Gaius que: «En efecto, el Derecho que cada pueblo se ha dado a sí mismo le es propio y se llama Derecho civil (ius civile), es decir, el Derecho propio de la ciudad (civitas), mientras que aquel Derecho que la razón natural (naturalis ratio) establece entre todos los hombres y es observado igual por todos los pueblos es llamado Derecho de gentes (ius gentium), es decir, el Derecho usado por todas las naciones (omnes gentes) $>^{5}$.

Igualmente señala que el derecho de gentes se llama así porque «casi todos los pueblos se guían por él». Así, la nota distintiva entre uno y otro es que mientras que el Derecho natural es el que surge del instinto natural, el de gentes surgiría del uso común y, por tanto, sería positivo. Esta es justamente la interpretación de Suárez cuando afirma que para Isidoro el Derecho de gentes «es un derecho común a todas las naciones y establecido no por inclinación de la sola naturaleza, sino por el uso de las naciones» ${ }^{6}$.

Durante el desarrollo del Derecho romano entra en juego la aplicación del ius civile como un derecho propio de la civitas romana, donde las relaciones con otras comunidades, en origen latinas y con posterioridad itálicas y mediterráneas, hizo necesario o bien el reconocimiento de los negocios realizados entre romanos y miembros de estas comunidades a través de la vía de la concesión del ius commercium o bien la formalización de tratados internacionales en los que se reconocía expresamente la validez de las relaciones comerciales a los ciudadanos de los pueblos firmantes.

Sin embargo, la realidad de un tráfico comercial y económico cada vez más fluido hizo que debiera acudirse a otro tipo de regulación, la cual se denominó ius gentium, cuya aplicación estuvo a cargo de una magistratura a la que se atribuye específicamente el conocimiento de los conflictos surgidos, especialmente en el ámbito de las relaciones patrimoniales, entre extranjeros y ciudadanos romanos y entre extranjeros entre sí. Esta institución se denominó pretura peregrina ${ }^{7}$.

Frente a todo ello podemos traer a colación lo abordado en las Institutas de Gayo 1.1.1 (De iure civile et naturale), donde se establece que:

5 D. A. HerRerA, «Ius Gentium, ¿Derecho natural o positivo?», disponible en bttps:// fccuniversitario.files.wordpress.com/2012/06/herrera-ius-gentium-derecho-natural-o-derechopositivo.pdf, p. 3.

${ }^{6}$ Ibid., p. 5.

7 A. FERnÁNDEZ DE BuJÁn, «Conceptos y dicotomías del ius», disponible en bttps://repositorio.uam.es/bitstream/handle/10486/3131/14198_3RJ008.pdf?sequence=1, p. 31 . 
«Todos los pueblos que se rigen por leyes y costumbres usan en parte su propio Derecho y en parte el Derecho común de todos los hombres, pues el Derecho que cada pueblo establece para sí, ese es suyo propio y se llama Derecho civil, como si dijéramos Derecho propio de la ciudad; en cambio, el que la razón natural establece entre todos los hombres, ese se observa uniformemente entre todos los pueblos y se llama Derecho de gentes, como si dijéramos el Derecho que usan todas las naciones. Así pues, el pueblo romano usa en parte su propio Derecho y en parte el Derecho común de todos los hombres» ${ }^{8}$.

Vemos, pues, cómo tanto el ius gentium como el ius commune serían el fundamento del Derecho romano, el cual durante muchos siglos se convirtió en un Derecho unificado ${ }^{9}$ que aún a día de hoy ha influenciado o es utilizado en cierta medida en la mayoría de los sistemas jurídicos del mundo.

Uno de los gregarios más destacados y conocidos del Derecho romano y del movimiento unificador fue el Código de Napoleón de 1804, el cual se concibió como un modelo jurídico para todas las naciones ${ }^{10}$. No sin vacilaciones se ha mencionado que el Derecho emanado de dicho Código ha sido el punto de referencia para numerosos legisladores extranjeros, contribuyendo a la creación de un orden jurídico internacional, y ha formado numerosas generaciones de estudiantes y profesores en el mundo con un método de razonamiento y una cultura jurídica propia ${ }^{11}$.

8 «Omnes populi, qui legibus et moribus reguntur, partim suo proprio, partim communi omnium hominum iure utuntur: nam quod quis que populus ipse sibi ius constituit, id ipsius proprium est nocaturque ius civile, quasi ius proprium civitatis; quod uero naturalis ratio inter omnes bomines constituit, id apud omnes populos peraeque custoditur uocaturque ius gentium, quasi quo iure omnes gentes utuntur. populus itaque Romanus partim suo proprio, partim communi omnium hominum iure utitur. quae singula qualia sint, suis locis proponemus».

9 Podríamos hablar aquí de la influencia que tuvo en la época el Derecho canónico, el cual, conjuntamente con el Derecho romano, eran las normas imperantes en toda la Europa occidental, siendo el canónico un Derecho unificado aplicable en los territorios donde tenía autoridad el papa incluso sobre los gobernantes, quienes obtenían la legitimación de aquel para poder gobernar en sus respectivos dominios. Una de las obras más representativas del Derecho canónico es el Decretum Gratiani, una obra bastante amplia e importante que unificó los textos de los once primeros siglos de la iglesia armonizándolos y unificándolos, convirtiéndolos en la obra de referencia sobre la materia. Vid. R. CABRILlAC, Las codificaciones, Santiago de Chile, Flandes indiano, 2009, pp. 21.

10 S. SoleIL, «¿Le Code Civil de 1804 a-t-il été concu comme un modele juridique pour les nations?», disponible en http://fbi.rg.mpg.de/debatte/Code 20Civil/pdf 20files/0503soleil.pdf.

${ }^{11}$ CONSEIL D'ETAT, «L'influence internationale du Droit français. La documentation française», Paris, 2001, disponible en http://www.ladocumentationfrancaise.fr/var/storage/ rapports-publics/014000702.pdf. 
Desde otro punto de vista, no puede darse de lado el aporte al tema en estudio por parte de Fiedrich Karl von Savigny, miembro de la llamada Escuela Histórica del Derecho, quien en un primer acercamiento y abiertamente en oposición al mismo señala en su obra Vocación de nuestro tiempo para la legislación y la jurisprudencia de 1814: «El supuesto general de este procedimiento es que cada pueblo tiene en su vida toda, y en especial también en su Derecho civil, una individualidad no meramente accidental, sino esencial y necesaria, fundada en todo su pasado, y que, por tanto, la invención de un Derecho común para todos los pueblos sería tan inútil como una lengua universal que hubiese de reemplazar las fuerzas vivas existentes ${ }^{12}$, ya que el Derecho positivo vive en la conciencia común del pueblo y, por tanto, tenemos que llamarlo Derecho popular» ${ }^{13}$.

Savigny, quien posteriormente cambia su postura radical inicial, afirma que no hay razón para que los jueces de cada Estado apliquen exclusivamente su ley territorial; en caso contrario, deberán desechar ese principio de territorialidad del Derecho y autorizar a los jueces el Derecho de todos los países, que forma un Derecho común emanado de la conciencia jurídica popular y formado en larga evolución bajo la influencia del cristianismo y del Derecho romano. Cada uno de los pueblos civilizados reconoce, en principio, el Derecho de otros pueblos civilizados y, así, en todos los Estados serán admitidos el uno a cambio del otro en condiciones de absoluta paridad, no pudiendo propiamente hablarse de territorialidad del Derecho ${ }^{14}$. En ese sentido vemos que Savigny intentó establecer una base científica para los conflictos de leyes que fuera congruente con la comunidad de Derecho entre los Estados cristianos independientes ${ }^{15}$.

A finales del siglo XIX, de la mano de la revolución industrial comienzan a darse los primeros intentos de unificación jurídica modernos ${ }^{16}$, ya que se venía previendo que el Derecho de los Estados debería unificarse ${ }^{17}$

12 E. Zuleta Puceiro, «Savigny y la teoría de la ciencia jurídica», Anuario de Filosofía del Derecho, núm. 19, p. 76, disponible en bttps://dialnet.unirioja.es/descarga/articulo/1985426.pdf.

13 F. J. Contreras, «La idea del espíritu del pueblo en F. C. v. Savigny», Anales de la Cátedra Francisco Suárez, núm. 35 (2001), p. 169, disponible en bttp://www.artic.ua.es/ biblioteca/u85/documentos/1794.pdf.

${ }^{14}$ F. C. von Savigny, Sistema de Derecho romano actual, edición de J. Mesía y M. Poley, vol. VIII, Alicante, Biblioteca Virtual Miguel de Cervantes, 2009, p. 28.

${ }^{15}$ F. Rigaux, «Codification of Private International Law: Pros and Cons», Louisiana Law Review, vol. 60, núm. 4 (2000), p. 1323.

16 En América Latina tenemos el Tratado de Derecho Internacional Privado de Montevideo de 1889.

17 S. KozUKA, «The Economic Implication of Uniform Law», Revue de Droit Uniform, vol. 4 (2007), p. 683. 
para que con ello se diera un impulso directamente al comercio internacional, y fue precisamente allí, en ese campo ${ }^{18}$, donde surgen instrumentos normativos que comienzan a unificarlo. Por otro lado, ya en 1893 se crea en los Países Bajos la Conferencia de La Haya de Derecho Internacional Privado ${ }^{19}$, la cual, como institución, ha dado nacimiento a un sinnúmero de convenios que han unificado dicha materia con un alcance internacional bastante importante.

Esa tendencia en cuanto a instituciones encargadas de la unificación y uniformización de normas jurídicas continuó teniendo eco a principios del siglo Xx, y es así como surge un nuevo representante, el Instituto para la Unificación del Derecho Privado (UNIDROIT) ${ }^{20}$, que se crea en Roma en 1926 bajo los auspicios de la entonces Sociedad de Naciones y culmina en el territorio europeo con la creación en el año 1966 de la Comisión de la Naciones Unidas para el Derecho Mercantil Internacional (CNUDMI) ${ }^{21}$. Al otro lado del Atlántico se crearon las Conferencias Especializadas de Derecho Internacional Privado (CIDIP), patrocinadas por la Organización de Estados Americanos (OEA), que se han ocupado de crear igualmente un sinnúmero de normas unificadas sobre la materia las cuales son de actual aplicación.

\section{El procedimiento de la unificación normativa}

La unificación como proceso sistemático puede ser entendida como un método mediante el cual se busca establecer, en una materia jurídica dada, una reglamentación detallada e idéntica en todos los aspectos y para todos los Estados que han participado en su elaboración y aceptado su contenido, dejando en algunos casos la elección de la modalidad bajo la cual debe darse su ejecución. En consecuencia, la unificación es por-

${ }_{18}$ Sin embargo, es curioso ver cómo en el continente europeo uno de los primeros instrumentos sobre la materia se dio el 2 de julio de 1890 cuando se firmó en Bruselas un Convenio internacional relativo a la esclavitud, al comercio y la importación hacia África de armas, municiones y licores. Mediante esta convención se unificaron normas, entre otras, para «poner fin a los crímenes y a las devastaciones que engendraron la trata de esclavos africanos y de proteger eficazmente las poblaciones aborígenes de África y de asegurarle a ese vasto continente los beneficios de la paz y de la civilización».

19 Primera conferencia citada por el gobierno neerlandés por iniciativa del jurisconsulto Tobías Michael Carel T. M. C. Asser. El sitio oficial es www.hcch.net.

${ }_{20}$ Para mayor información vid. www.unidroit.org.

21 El sito oficial es www.uncitral.org. 
tadora de una unificación legislativa de segundo grado incrustada en un sustrato flexible ${ }^{22}$.

En este contexto es importante señalar que puede darse una distinción entre ese Derecho uniforme, integrado por un conjunto de normas adoptadas por un grupo de Estados que mantiene una voluntad común de someterse a una misma reglamentación en determinadas relaciones jurídicas, y aquel que hace referencia al resultado normativo en el que desemboca un proceso de unificación del Derecho, que puede materializarse a través de distintos cauces (leyes modelo, leyes uniformes, tratados de unificación, etc.) y en determinados círculos jurídicos con un alto grado de integración ${ }^{23}$.

Se entiende, pues, que por medio de la unificación de normas ${ }^{24}$ lo que se busca en esencia es suprimir o adaptar las normas internas que regulan una materia, en especial mediante una reglamentación más estandarizada que pueda ser aplicable en aquellos ordenamientos jurídicos que se conectan mediante situaciones jurídicas o mediante relaciones interestatales, como puede ser el caso de compraventas internacionales de mercaderías.

Por otro lado, si aplicamos el concepto de unificación al Derecho, tal vocablo puede indicar que hay una sustitución de dos o más sistemas jurídicos por un único sistema; en este caso estaríamos en presencia de la unificación en sentido estricto. En un sentido amplio, la unificación del Derecho abarca todo proceso destinado a garantizar que normas legales con el mismo contenido se inserten en dos o más sistemas jurídicos. Esto impli-

${ }^{22}$ I. F. KAMDE, «Harmonisation, unification et uniformisation. Plaidoyer pour un discours affiné sur les moyens d'intégration juridique», Revue de Droit Uniforme, vol. 13, núm. 3 (2008), p. 619.

${ }^{23}$ J. C. FERnÁndez Rozas, «Los procesos de unificación internacional del Derecho privado: técnicas jurídicas y valoración de resultados», en J. M. García Collantes (ed.), La unificación jurídica europea. Seminario organizado por el Consejo General del Notariado en la UIMP, Madrid, Civitas, 1999, p. 36.

${ }^{24}$ René David va más allá y considera que puede haber una unificación cuando se adopta una actitud común frente al Derecho y, por ejemplo, cuando se toma un sistema, un conjunto de métodos y conceptos. Puede haber unificación mediante la introducción de un vocabulario uniforme (incoterms); mediante una presentación estándar de las diferentes soluciones; por leyes modelo con una organización internacional a la cual se le notificarían los cambios que se vayan produciendo; por contratos tipo que incluso pueden ser desarrollados por una organización empresarial dentro de una organización, como la Comisión Económica de las Naciones Unidas para Europa, o por otro organismo, como COMECON, etc. La unificación del Derecho, por tanto, es un área muy amplia que tiene aspectos muy variados. Vid. A. Tunc, «Standards juridiques et unification du droit», Revue Internationale de Droit Comparé, vol. 22, núm. 2 (1970), pp. 247-261, disponible en bttp://www.persee.fr/ docAspdffridc_0035-337_1970_num_22_2_15698.pdf. 
ca la conservación de la pluralidad formal de estos sistemas de Derecho, a diferencia de la aplicación más restrictiva ${ }^{25}$.

Una parte de la doctrina estima que en lugar de hablar de unificación internacional debería referirse mejor al término de mundialización de reglas del Derecho, ya que mediante tal expresión se podría definir el fenómeno que esta conlleva, donde no solo se aplica la unificación de las reglas, sino su armonización, su coordinación, su acercamiento, su uniformización y su interpenetración ${ }^{26}$. También es necesario anotar que esa «mundialización» abarca bastantes ramas del Derecho, como son, entre otras: el Derecho mercantil internacional ${ }^{27}$, el Derecho de las personas en materia de alimentos ${ }^{28}$, el Derecho sobre adopción ${ }^{29}$, el Derecho sobre secuestro internacional de menores ${ }^{30} \mathrm{o}$ el Derecho laboral ${ }^{31}$, entre otros. Lo anterior lleva a que se presente un reacomodamiento de los diferentes ordenamientos jurídicos nacionales, lo que conlleva necesariamente una mundialización de los conceptos legales ${ }^{32}$.

En este sentido son adecuadas las palabras del profesor Audit cuando señala que:

«Hay que decir que cualquier intento de globalización de la ley tiene como objetivo general facilitar las transacciones y las relaciones internacionales y garantizar su seguridad jurídica. Sin embargo, es en los campos comerciales y económicos donde la incapacidad de las leyes nacionales para abordar y solucionar los problemas planteados por este tipo de relaciones y transacciones se hace sentir con más evidencia y acuidad. Es igualmente en estas áreas donde los gobiernos y organismos internacionales, tanto gubernamentales como no gubernamentales, parecen ser más activos en cuanto al desarrollo de diversos instrumentos legales respecto a la mundia-

${ }_{25}$ A. MAditoppI, «Les relations entre l'unification et I'harmonisation du Droit et la technique de l'unification ou de l'armonisation par voie d'accords internationaux», Unification du Droit (1967-1968), p. 43.

${ }_{26}$ M. Paquette, «La mondialisation des règles de Droit: ¿coercition ou liberté?», $X I^{e}$ Conference des Juristes de l'État, p. 181, disponible en bttp://www.conferencedesjuristes. gouv.qc.ca/files/documents/8l/40/lamondialisationdesreglesdedroit.pdf.

${ }_{27}$ Convención de Viena de 1980 sobre la compraventa internacional de mercaderías.

${ }^{28}$ Convenio de La Haya de 2 de octubre de 1973 sobre ley aplicable a las obligaciones alimenticias.

29 Convenio de La Haya de 29 de mayo de 1993 relativo a la protección del niño y a la cooperación en materia de adopción internacional (Convenio de La Haya sobre Adopción).

${ }^{30}$ Convenio de La Haya de 25 de octubre de 1980 sobre los aspectos civiles de la sustracción internacional de menores.

31 Los diferentes Convenios de la OIT.

32 M. Paquette, «La mondialisation des règles de Droit...», op. cit., p. 189. 
lización del Derecho. Algunos han llegado a afirmar que en el ámbito del Derecho privado, el Derecho sustancia uniforme permanece circunscrito al comercio» ${ }^{33}$

El profesor Pereznieto, haciendo referencia al tema y de una manera tangencial, habla del «trasplante» $\mathrm{o}$ «Cross Fertilization» de ordenamientos jurídicos de un sistema jurídico a otro por razones distintas (por ejemplo, la admiración que se tiene por un determinado sistema jurídico cuyo funcionamiento se piensa que va a ser semejante en sus resultados si se «trasplanta» a un sistema jurídico diferente). En otras palabras, se trata de enlazar el sistema jurídico nacional antes cerrado con el mundo a través de regulaciones más avanzadas que ya han probado su eficiencia en la práctica ${ }^{34}$.

Vemos, pues, cómo las relaciones jurídicas internacionales necesitan de un constante intercambio no solo de aire, sino de opiniones; de ahí que, para poder progresar, el Derecho como tal tiene la necesidad de evadirse de las fronteras nacionales en las cuales ha permanecido durante mucho tiempo encerrado y que de alguna manera le han creado ciertas patologías, por lo que se hace necesario que se mezcle con otros y adquiera una nueva dimensión. Al fin de cuentas el desarrollo del Derecho está al servicio de la comunidad misma y no tanto de una elite política que decida en qué momento se exteriorice de acuerdo a sus intereses propios ${ }^{35}$.

En muchos casos, la interrelación y la aplicación de un Derecho uniforme en un ordenamiento jurídico interno puede tomar diferentes cauces ${ }^{36}, \mathrm{y}$ ello es así porque la elección del mismo se suele dejar en manos de los políticos, de quienes dependerán los parámetros que suelen influir en la mayoría de las organizaciones internacionales que abordan la materia. Es por esto que se debe tener en cuenta el nivel de desarrollo económico de las naciones, sus preferencias axiológicas, así como sus aspiraciones sociales ${ }^{37}$.

33 B. Audit, «Flux et reflux de la crise des conflits de lois», Travaux du comité français de Droit international privé. Journée du cinquantenaire. Problèmes actuels de méthode en Droit international privé, Paris, Centre National de la Recherche Scientifique, 1988, p. 60.

${ }^{34}$ L. Pereznieto Castro, «La revolución del Derecho internacional privado en el mundo de hoy», Anuario Hispano-Luso-Americano de Derecho Internacional, vol. 21 (2013), p. 410 .

${ }^{35}$ F. Rigaux, «Les incidences des conventions internationales en Droit interne», disponible en bttp://rbdi.bruylant.be/public/modele/rbdi/content/files/RBDI\%201966/RBDI\%20 1966-1/Informations/RBDI\%201966.1\%20-\%20pp.\%20278\%20\%C3\%A0\%20298\%20 -\%20informations.pdf, p. 279.

36 J. BASEDOw, «The Renascense of Uniform Law. European Contract Law and its Components», Legal Studies, vol. 18, núm. 2 (1998), p. 121.

37 I. F. KAMDE, «Harmonisation, unification et uniformisation...», op. cit., p. 606. 


\section{Creación del Derecho uniforme}

La forma más común y típica de crear Derecho uniforme es a través de los convenios internacionales llevados a cabo entre los Estados o mediante la elaboración de un instrumento normativo por parte de un organismo internacional especializado en la materia que se encargue de elaborarlo y luego ponerlo a disposición de los Estados Parte para que se apruebe o no el contenido de este.

En este aspecto apoyamos la posición de Bonell, quien indica que nuestros tiempos se caracterizan por una multiplicidad de iniciativas dirigidas a la unificación —o al menos a la armonización — de las leyes nacionales. Ya no es posible contar el número de convenciones internacionales, leyes uniformes, códigos y reglas de conducta que tratan de regular los aspectos más variados no solo del Derecho privado, sino también del Derecho público mediante normas uniformes destinadas también a satisfacer necesidades prácticas. A veces las convenciones individuales y las leyes uniformes apuntan a una aplicación universal, mientras que otras solo se aplican a grupos definidos de Estados o regiones. En algunos casos tratan de sustituir por completo el Derecho interno correspondiente, mientras que en otros su objetivo es simplemente regular las relaciones internacionales (el Derecho interno paralelo sigue regulando las relaciones puramente internas). Otra distinción se refiere a la aplicabilidad de la ley uniforme ${ }^{38}$.

Se busca con este proceso, el cual puede incluir la unificación y la armonización, la sustitución por normas que mejores aquellas existentes en los sistemas jurídicos de los Estados individuales. Por «normas mejores» deben entenderse las reglas que elevan la categoría del statu quo con respecto a algún objetivo social normativo, como la justicia redistributiva o la mejora del bienestar económico. Aquí se mezclan los objetivos de la armonización y la reforma legislativa. Frente a lo anterior pueden surgir inmediatamente preguntas desconcertantes tales como: ¿qué distingue la elaboración de una norma internacional de aquella de una nacional? ¿Cuándo podría prosperar una implementación normativa a partir del Derecho internacional cuando los esfuerzos nacionales han fracasado?

38 M. J. BonelL, «International Uniform Law in Practice - Or Where the Real Trouble Begins», American Journal of Comparative Law, núm. 38 (1990), pp. 865-888, disponible en bttp://www.cisg.law.pace.edu/cisg/biblio/bonell2.html. 
Frente a las cuestiones anteriores pueden existir divergencias en cuanto al hecho de que se afirme que en los proyectos internacionales para unificar y armonizar el Derecho se goce de mejores ventajas, en especial en lo que hace relación a la calidad del material disponible y a la experiencia de quienes participan en su elaboración. Sin embargo, no puede desecharse la idea de que un proyecto de reforma legal puramente nacional también puede recurrir a una amplia gama de talentos legales locales y emplear un análisis comparativo para determinar reglas óptimas que puedan ser aplicadas en dicho ordenamiento jurídico ${ }^{39}$.

Somos de la idea de que los instrumentos internacionales, salvo algunas excepciones que posteriormente se pueden mencionar, pueden proporcionar soluciones más correctas, estructuradas y eficaces a casos con elementos internacionales que lo que el propio Derecho interno podría hacer; todo esto sin tocar temas tan sensibles como pueden ser la dignidad y la independencia del sistema jurídico local. De hecho, se puede afirmar que en el Derecho unificado son más las ventajas que las desventajas en cuanto a los resultados que se obtienen con su aplicación. Sin embargo, somos conscientes que parte de la reticencia en cuanto a su aplicación puede venir por parte de grupos que tienen intereses particulares, incluso políticos ${ }^{40}$, que aprovechan cualquier oportunidad para denigrar tal normativa y pedir constantemente su exclusión del sistema jurídico local.

En este contexto vemos cómo un convenio internacional sobre la materia busca esencialmente uniformizar aquellas normas que son aplicables en diferentes campos (como el económico, el familiar, el laboral, etc.). En otros términos, lo que se busca es establecer reglas comunes que se puedan integrar con el Derecho interno de los Estados; de donde se puede pregonar que la incidencia del convenio internacional sobre el Derecho interno es totalmente evidente y que el único problema que puede ocasionar será aquel de determinar cuál será la extensión de dicha acción —en consecuencia, sus límites-. A este proceso de unificación se une el de la armo-

39 P. B. Stephan, «The Futility of Unification and Harmonization in International Commercial Law», University of Virginia School of Law Legal Studies Working Papers Series, 1999, p. 6, disponible en http://papers.ssrn.com/paper.taf?abstract_id $=169209$.

${ }_{40} \mathrm{Al}$ respecto señala Stephan: «Si el proceso de unificación necesariamente tiene que sacrificar algo en el camino de la rendición de cuentas puede compensarlo explotando los conocimientos técnicos de una forma más amplia de lo que los legisladores nacionales normalmente lo hacen. Libre de obstáculos políticos insignificantes, los expertos comprometidos en la redacción de leyes unificadas pueden tener la libertad de elaborar borradores sofisticados y equilibrados que anticipen y resuelvan una amplia gama de problemas potenciales». Vid. ibid., p. 8. 
nización, el cual busca hacer desaparecer las diferencias entre las legislaciones internas sin llegar hasta el punto de la unificación ${ }^{41}$.

Es por ello que para que una norma uniforme pueda continuar expresando un derecho similar en los distintos países donde ella es parte de su ordenamiento jurídico es necesario que se hayan producido decisiones judiciales al respecto, si no resulta inútil su aplicabilidad. De hecho, para que una ley sea uniforme no necesariamente se necesita que sea uniformemente aplicada e interpretada por los jueces; ello es así porque lo anterior conduciría a ignorar las peculiaridades del razonamiento jurídico y el poder creativo de la actividad del juez, ya que no puede pensarse siquiera por un instante que la interpretación de textos similares conduciría inexorablemente a los mismos resultados. Igualmente, un convenio internacional no tiene por objetivo establecer reglas comunes que tengan un lugar en el Derecho interno, sino determinar los objetivos comunes a la política económica y social de los países interesados ${ }^{42}$.

Como se puede apreciar, un convenio internacional tiene, en todo caso, una incidencia fundamental en el Derecho interno de los países firmantes. Este impacto se manifiesta ya sea a través de la uniformización, la armonización o la transformación de la legislación interna con el fin de garantizar la coherencia del sistema legal, o mediante la solución de las antinomias resultantes entre la aplicación de la norma uniforme y aquella de Derecho interno ${ }^{43}$.

Es sabido que la adopción por parte de un Estado de un texto uniforme no es muy del agrado de sus dirigentes políticos y de algunos académicos que no fueron invitados a participar en la elaboración del mismo, y es por eso que para no verse comprometidos en la adopción e incorporación de dicho instrumento en su ordenamiento jurídico acuden a tomar «prestadas» las llamadas «leyes modelo», que igualmente son elaboradas por organismos internacionales o en el seno de una conferencia internacional, pero cuya particularidad es que no tienen un carácter obligatorio directo, son moldeables (Soft law) y pueden inspirar al legislador interno a la hora de codificar una determinada materia cubierta por dicha ley modelo ${ }^{44}$.

${ }^{41}$ F. Rigaux, «Les incidences des conventions...», op. cit., p. 283.

42 P. FORIERS, «L'incidence des conventions internationales sur le Droit commercial», p. 286, disponible en bttp://rbdi.bruylant.be/public/modele/rbdi/content/files/ RBDI\%201966/RBDI\%201966-1/Informations/RBDI\%201966.1\%20-\%20pp.\%20278\%20 \%C3\%A0\%20298\%20-\%20informations.pdf.

${ }^{43}$ Ibid., p. 290.

${ }^{44}$ J. C. FernándeZ RozAs, «Los procesos de unificación internacional...», op. cit., p. 29. 
La unificación del Derecho y la armonización de los Derechos en cierta medida se imponen como mecanismos indispensables, si no esenciales, en la necesaria aproximación de las legislaciones. Su objetivo sigue siendo el mismo: lograr una mejora considerable en las situaciones jurídicas decodificando la diversidad que caracteriza las legislaciones internas de los Estados (cada una con relación a las demás). Pero en contra de este denominador, que es común a todos, la unificación y armonización conservan características propias en muchos aspectos, sobre todo en su propia noción, además también de compartir los mismos métodos o instrumentos con relación a su ejecución ${ }^{45}$.

Por ello es claro señalar que, en este entorno, la uniformización del Derecho puede entrelazarse con otros aspectos no solo de la vida jurídica de los Estados, sino que la misma es inseparable de la cooperación económica internacional y del progreso de estos por medio de su desarrollo armónico con el Derecho interno. Por eso ha de afirmarse que, más que nunca, la claridad y la homogeneidad son atributos esenciales del Derecho, cuyo fin en la concepción que de él tenemos será el de proteger y ayudar a los más débiles ${ }^{46}$.

Una vez se ha producido la sistematización, sus normas solo entran en vigor después de su introducción en los ordenamientos jurídicos individuales mediante el procedimiento de ratificación adecuado. Existen, sin embargo, ejemplos de normas internacionales uniformes que, una vez aprobadas por los órganos competentes de las organizaciones supranacionales o comunitarias, son inmediatamente aplicables (este es el caso de los tratados o convenios self executing, los cuales no requieren de ningún otro proceso para ser efectivos en los Estados que los han adoptado). Por último, puede haber reglas modelo que no tienen fuerza vinculante, cuya introducción en los distintos sistemas nacionales se deja enteramente a la discreción de los Estados para que las tomen como ejemplo al crear normas internas similares.

45 A. SeRge Kablan, «L'uniformisation régionale du droit: processus comparés et Projet de l'OHADA en transport routier», Mémoire présenté à la Faculté des études supérieures de l'université Lavai, p. 15, disponible en http://www.collectionscanada.gc.ca/obj/s4/f2/ dsk2/ftp03/MQ55591.pdf.

46 B. Boutros-GHALI, «Discours d'ouverture. Le Droit commercial uniforme au XXI siècle», en Actes du Congrès de la Commission des Nations Unies pour le Droit commercial international, New York, Publication des Nations Unies, 1995, p. 2. 


\section{Organismos creadores de Derecho uniforme}

Como ya señalamos con anterioridad, las organizaciones internacionales creadoras de Derecho uniforme aparecen básicamente a finales del siglo XIX y en el XX, estando en primer lugar la Conferencia de La Haya de Derecho Internacional Privado, el Instituto para la Unificación del Derecho Privado (UNIDROIT), la Comisión de la Naciones Unidas para el Derecho Mercantil Internacional [CNUDMI (UNCITRAL)], la Cámara de Comercio Internacional, las Conferencias Interamericanas de Derecho Internacional Privado (CIDIP), el American Law Institute (ALI) y la Organización para la Armonización en África del Derecho Mercantil (OHADA), las cuales, de una manera estructurada y organizada, han estado desarrollando normas que facilitan no solo la convivencia entre los Estados, sino las relaciones comerciales entre los mismos.

Estimamos que estas organizaciones, tanto por su vocación universal como regional, reflejan que sus intereses son meramente académicos y desprovistos de cualquier tinte político que pueda interferir en el fin último de la normativa, que no es otro que el de brindar previsibilidad y seguridad jurídica ${ }^{47}$ sin importar el lugar donde se encuentren las personas que reclaman ese derecho, sobre todo en épocas de la globalización donde se hace necesario cierta estandarización legal que facilite las relaciones interpersonales, económicas y sociales, y evite de esa manera las incertidumbres propias de sistemas jurídicos desconocidos para quienes llegan a un territorio con el fin de establecer intercambios con sus habitantes o dependencias gubernamentales o empresas privadas ${ }^{48}$.

${ }^{47}$ J. O'Honnold, Objectifs de l'Unification. Le Droit commercial uniforme au XXI siècle. Actes du Congrès de la Commission des Nations Unies pour le Droit commercial international, 1992, New York, Nations Unies, 1995, p. 12, disponible en bttps://www.uncitral.org/ pdf/french/texts/general/Uniform_Commercial_Law_Congress_1992_f.pdf.

48 En un estudio llevado a cabo sobre el rol de tales organizaciones, Scotti indica que: «Aun cuando se superpongan los trabajos de organizaciones de carácter universal o de una de estas con otra de vocación regional, ello puede no resultar contraproducente si, en lugar de verlo como una "duplicación de trabajo", se lo observa como un conjunto de múltiples esfuerzos compartidos que, de ser coordinados, podrían ser capaces de obtener óptimos resultados e incluso de elaborar soluciones universalmente aceptables que brinden la tan anhelada seguridad jurídica a las personas humanas, quienes, en definitiva, deben ser los destinatarios principales de tales esfuerzos». Vid. L. B. ScotTi, El rol de los organismos internacionales en la armonización del Derecho internacional privado, Buenos Aires, Centro Argentino de Estudios Internacionales, p. 40, disponible en bttp://w1.cejamericas.org/index. php/biblioteca/biblioteca-virtual/doc_view/6537-el-rol-de-los-organismos-internacionales-enla-armonizaci\%C3\%B3n-del-derecho-internacional-privado.btml. 


\section{Interpretación del Derecho uniforme}

Uno de los grandes problemas que suscita la aplicación del Derecho uniforme es su interpretación por parte de los tribunales ${ }^{49}$ o autoridades que están encargadas de hacerlo y frente a una situación jurídica determinada, y ello es así porque se estima, en la mayoría de la veces, por parte de aquellos que lo más natural en estos casos es recurrir a una fuente conocida y familiar, lo que los conducirá indefectiblemente a consultar su Derecho interno (lege fori), sin muchas veces tomarse el esfuerzo de preguntarse si tal situación tendría una mejor solución si fuese interpretada a la luz de lo contenido en la normativa uniforme (lege causae) ${ }^{50}$.

$Y$ es que en muchas ocasiones las dificultades relacionadas con la incorporación de los tratados o convenciones en el orden interno de los Estados que han prestado su consentimiento en obligarse por los mismos no son pocas; la misma se vincula a la recepción y aceptación del Derecho uniforme por los jueces nacionales, autoridades administrativas e incluso árbitros en el proceso de aplicación del Derecho. El juego de las reservas, la interpretación judicial a través de categorías jurídicas del foro o la eventual acción del orden público son elementos que dificultan la puesta en práctica de una sana asimilación del Derecho unificado por parte de las instancias nacionales. Finalmente, el mecanismo de las cláusulas del instrumento internacional que contiene el resultado unificador en lo que respecta a los ámbitos de aplicación material, temporal y territorial del convenio, tampoco contribuye a una difusión de este particular conjunto normativo ${ }^{51}$.

Por eso, y en cuanto a la forma cómo debe abordarse e interpretarse el Derecho uniforme o convencional, tenemos que la mayoría de los textos

49 A menos que sea un tribunal establecido al efecto, como es el caso del Tribunal de Justicia de la Comunidad Europea, que es el encargado de interpretar los acuerdos a que están sometidos los países miembros de la Unión Europea, es decir, el Derecho comunitario. En el caso del Mercosur está el Tribunal Permanente de Revisión del Mercosur.

50 «La dialéctica entre las normas internas y las unificadoras es un hecho indiscutible, pues la soberanía del Estado sigue constituyendo un importante freno a cualquier proyecto unificador. Una ley, por técnica que sea en apariencia, es siempre la traducción de una política y de unos intereses, y su unidad supone un objetivo común, lo que requiere la unidad de soberanía excluida por hipótesis. No en vano los autores internacionalistas han tenido que reconocer que la unificación del Derecho se presenta siempre como algo inacabado y no puede excluir de ninguna forma el eventual empleo del Derecho internacional privado conflictual». Vid. J. C. FERnÁNDEZ ROZAS, «Los procesos de unificación internacional...», op. cit., p. 31.

${ }_{51}$ A. MalintopPI, «Mesures tendant à prévenir les divergences dans l'interprétation des règles de Droit uniforme», Yearbook of the International Institute for the Unification of Private Law, 1959, p. 43. 
contentivos de la materia dictaminan que debe acudirse en primera instancia a la autointerpretación, que es una sus particularidades más importantes, la cual radica en el hecho de que esta clase de normas deben interpretarse a la luz del texto mismo del convenio ${ }^{52}$, y solo en casos determinados donde no es posible tal interpretación se señala a dónde se debe acudir para poder brindar una solución acorde a las necesidades de quienes reclaman la aplicación de esa normativa; tal redireccionamiento será, en esencia, hacia los principios generales del Derecho, la costumbre internacional, los usos comerciales, la jurisprudencia, la doctrina y, en último lugar, donde se debe recurrir para interpretarlo es al Derecho interno ${ }^{53}$ del Estado donde se ha puesto de relieve tal interpretación.

Como sabemos, en estos eventos ha de emplearse una terminología jurídica neutra que no afecte intereses particulares, sino que propenda a un acercamiento de los diferentes conceptos en juego para hallar el que mejor se adapte a la situación jurídica que ha de ser elucidada y resuelta por los encargados de brindar la justicia que se busca. Es importante que el resultado esté acorde no solo con lo buscado por las partes, sino con lo querido por los operadores jurídicos, ya que interpretar es esencialmente adaptar una situación jurídica a un esquema local donde esta busca producir efectos o resultados razonables ${ }^{54}$.

52 La mayoría de los convenios internacionales señalan tal obligación, entre ellos el art. 7 de la Convención de Viena de 1980 sobre la compraventa internacional de mercaderías: «1) En la interpretación de la presente Convención se tendrán en cuenta su carácter internacional y la necesidad de promover la uniformidad en su aplicación y de asegurar la observancia de la buena fe en el comercio internacional. 2) Las cuestiones relativas a las materias que se rigen por la presente Convención que no estén expresamente resueltas en ella se dirimirán de conformidad con los principios generales en los que se basa la presente Convención o, a falta de tales principios, de conformidad con la ley aplicable en virtud de las normas de Derecho internacional privado». En el mismo sentido, art. 1.6 de los Principios UNIDROIT sobre los contratos comerciales internacionales; art. $4 .^{\circ}$ de la Convención Interamericana sobre derecho aplicable a contratos internacionales de 1994; art. 23 del Convenio de La Haya de 30 de junio de 2005 sobre acuerdos de elección de foro, y art. 53 del Convenio de La Haya de 23 de noviembre de 2007 sobre cobro internacional de alimentos para los niños y otros miembros de la familia.

53 Esto no quiere decir que la normativa nacional no pueda aportar una solución más eficaz al problema planteado; sin embargo, estimamos que primero se deben agotar otros recursos antes de acudir a esta clase de normas. Algunos autores estiman que se debe acudir primeramente a la ley local para tratar de buscar allí una solución que el Derecho uniforme no aporta. Vid. H. Snijders y S. Vogenauer, Content and Meaning of National Law in the Context of Transnational Law [Interpretation of UNIDROIT Principles of International Commercials Contracts by national Courts], München, European Law Publishers, 2009, p. 169.

${ }^{54}$ F. EnderLeIn, Uniform Law and its Application by Judges and Arbitrators. International Uniform Law in Practice, Oxford, Oxford University Press, 1987, p. 332, disponible en http://www.cisg.law.pace.edu/cisg/biblio/enderlein.pdf. 
Algunos autores sostienen, en una posición opuesta al anterior planteamiento, que «la unificación del Derecho debería comportar la identidad absoluta del contenido de las normas jurídicas que son objeto». En la práctica, sobre todo internacional, a menudo se recurre a los órganos del Estado para llevar a cabo la inserción de textos uniformes en las leyes nacionales: a esto lo llamamos «proceso de adaptación» de las normas internas a los procesos normativos a nivel internacional. Ahora bien, ¿quién dijo que la «adaptación» implicaba también necesariamente la «interpretación»? Aquí radica una de las fuentes de los problemas más espinosos que conlleva el análisis del Derecho uniforme que amenaza constantemente la vocación de este ${ }^{55}$.

\section{Características del Derecho uniforme}

El Derecho uniforme moderno como tal difiere del Derecho interno esencialmente en cuanto a su forma de elaboración, la cual está ligada estrechamente con la reunión y estudio por parte de un grupo de expertos para analizar una materia determinada, la mayoría de las veces bajo el patrocinio de un organismo multilateral que ve la necesidad de implementar un cuerpo de normas que pueda dar solución a determinados problemas jurídicos que se suscitan en el tráfico externo y que no pueden ser abordados por el Derecho interno, el cual regula o no regula la cuestión, $\mathrm{o}$, si lo hace, lo hace de una forma precaria o con un alcance limitado a su esfera territorial. En este caso ese «nuevo Derecho fusionado» regulará la cuestión tanto desde un punto de vista interno como externo.

El Derecho uniforme es inicialmente un derecho extrafronteras que mediante su incorporación se convierte posteriormente en un Derecho interno, lo cual hace que el mismo tenga un contenido material propio, de donde se desprende que sus normas serán aplicables directamente a la situación jurídica que ha de ser dilucidada por el operador jurídico que tenga a cargo la solución de la misma.

Si bien, como afirmamos en este caso, el Derecho uniforme moderno es obra de organismos o instituciones especializadas internacionales, lo que le da un carácter universal o regional, nada obsta para que este sea el producto de un acuerdo entre dos o más Estados para regular un tema determinado, lo que limita su aplicación ratio materiae al territorio de aquellos

55 A. MalintopPI, «Mesures tendant à prévenir les divergences...», op. cit., p. 249. 
que han adoptado el mismo; en consecuencia, su alcance será más limitado para este tipo de $\operatorname{casos}^{56}$.

\section{Incorporación del Derecho uniforme en el Derecho interno}

Para que el Derecho uniforme pueda ser efectivo y cumplir el propósito para el que fue creado debe recorrer un proceso mediante el cual este entra a formar parte del Derecho interno del Estado que ha decidido adoptarlo, es decir, debe incorporarse cumpliendo los requisitos que se exijan para esta clase de actos y de acuerdo a las exigencias del ordenamiento jurídico donde se vaya a implementar, ya que para que sea efectiva su aplicación debe ser reconocida como tal en dicho territorio.

En muchos casos, el Derecho uniforme o convencional debe someterse al procedimiento legislativo, donde se le otorgará la categoría jurídica con la que ingresa al ordenamiento jurídico, esto es, si se trata de una ley ordinaria o si, por el contrario, se trata de una ley con rango constitucional o supraconstitucional, como puede ser el caso de tratados o convenios que protegen los derechos humanos (en estos casos podrá tener aplicación el principio general denominado specialia generalibus derogant).

Por otro lado, cuando el Derecho uniforme proviene de un uso o costumbre internacional, como es el caso de la lex mercatoria ${ }^{57}$ (cuya creación puede no estar adscrita a ningún organismo internacional), es necesario que el operador jurídico lo incorpore a ese ordenamiento legal no por la vía tradicional — que es mediante la refrendación legislativa—, sino que su inserción se hace cuando el mismo Derecho interno autoriza su aplicación en una situación que presente tal particularidad ${ }^{58}$ y que únicamente pueda ser resuelta con aquella norma de carácter consuetudinario para que puedan ser efectivos los postulados de Derecho uniforme.

56 J. C. FERnÁNDEZ RoZAS, «Consideraciones en torno a la relevancia del Derecho uniforme en la regulación del tráfico privado externo», en J. L. IGLESIAS PRADA (coord.), Estudios jurídicos en homenaje al profesor Aurelio Menéndez, t. IV, Madrid, Civitas, 1996, p. 5210.

57 Puede ser el caso de la Convención de Viena de 1980 sobre la compraventa internacional de mercaderías, cuando un Estado que no la ha ratificado la utiliza como costumbre internacional (en este caso tiene aplicabilidad su art. $9 .^{\circ}$ ). En el mismo sentido tenemos también los denominados incoterms de la Cámara de Comercio Internacional.

${ }^{58}$ Un ejemplo de ello lo podemos encontrar en el art. 7. ${ }^{\circ}$ del Código de Comercio colombiano que señala: «Los tratados o convenciones internacionales de comercio no ratificados por Colombia, la costumbre mercantil internacional que reúna las condiciones del art. $3^{\circ}$, así como los principios generales del Derecho comercial, podrán aplicarse a las cuestiones mercantiles que no puedan resolverse conforme a las reglas precedentes». 


\section{PROBLEMAS DE LA INCORPORACIÓN DEL DERECHO UNIFORME}

Cuando conviven en un mismo ordenamiento jurídico dos normativas, esto es, Derecho uniforme y Derecho interno, y ambas se proyectan como idóneas para abordar y quizá resolver una situación jurídica dada, en muchas ocasiones se presenta la situación de que ninguna de las dos lo haga de manera completa. En este caso el juez u operador judicial debe acudir a una operación híbrida, donde lleva a cabo una «especie de mezcla» de ambas regulaciones para poder hallar y brindar una mejor solución al caso propuesto. Lo anterior nos puede llevar a pensar que en esta clase de situaciones es muy difícil resolver un litigio con una única normativa, en especial desde el punto de vista del Derecho uniforme, ya que difícilmente se encontrará una decisión judicial o administrativa que tenga como fundamento único al Derecho uniforme y que se halle en un estado de total pureza, sin ningún tipo de contaminación por parte del Derecho interno ${ }^{59}$.

En este mismo sentido, consideramos que no es lo mismo la actitud que tome un juez o una autoridad administrativa frente a la que tome un árbitro, ya que la realidad nos ha demostrado que este puede disponer de más libertad para utilizar ciertos recursos provenientes de Derecho extranjero, cosa que para el juez u otro funcionario no les es tan fácil, en especial cuando las partes, sobre todo en materia contractual, pueden escoger libremente el Derecho que va regir su relación obligacional ${ }^{60}$, el cual puede ser diferente al del Estado del foro e incluso uniforme.

59 «Constituye un hecho indiscutible la dialéctica entre las normas internas y las unificadoras, pues la soberanía del Estado sigue constituyendo un importante freno a cualquier proyecto unificador. Ciertamente, una vez que se ha introducido en el sistema jurídico de un Estado el Derecho uniforme se convierte en "Derecho nacional"; no obstante, sigue conservando ciertas peculiaridades, derivadas de su especial proceso de elaboración, que no responde a unos principios jurídicos únicos, sino que es el resultado de una acomodación de intereses realizada por obra de la cooperación internacional; dichas peculiaridades se manifestarán, como es lógico, a la hora de la interpretación. Además, una ley, por técnica que sea en apariencia, es siempre la traducción de una ideología y de unos intereses y su unidad supone una política común, lo que requiere la unidad de soberanía excluida por hipótesis. No en vano un autor internacionalista de la categoría de J. A. Carrillo Salcedo ha tenido que reconocer que la unificación del Derecho se presenta siempre como algo inacabado y no puede excluir de ninguna forma el eventual empleo del Derecho internacional privado». Vid. J. C. FERNÁNDEZ ROZAS, «Consideraciones en torno a la relevancia del Derecho uniforme...», op. cit., p. 5218.

${ }^{60}$ Un ejemplo de ello lo podemos encontrar en el art. 3. ${ }^{\circ}$, núm. 1, del Convenio de Roma de 1980 sobre la ley aplicable a las obligaciones contractuales, que indica: «Art. 3. Libertad de elección.-Los contratos se regirán por la ley elegida por las partes. Esta elec- 
$\mathrm{Y}$ es que en estos eventos existe un temor reverencial, especialmente por parte de los jueces y otros funcionarios administrativos, al aplicar el Derecho uniforme, a menos que se haya tenido una formación específica con relación a la materia, en cuya situación podríamos decir que están mejor habituados a ello, pero en muchos países esto es la excepción, ya que la realidad muestra que cada día es mayor el número de normas que deben aplicar los jueces, las cuales, en el caso del Derecho uniforme, como es un derecho que «acaba de llegar», en muy pocas ocasiones se le realiza un verdadero proceso de incorporación al orden jurídico en un sentido estricto, esto es, una mutación entre las normas, sino que se le deja al lado y no se le jerarquiza, lo que en muchas ocasiones conlleva que no esté al alcance de quien debe aplicarlo.

Por otro lado, por muy bien elaborada que se encuentre la normativa uniforme, esta debe armonizarse con la normativa interna existente, y eso es un proceso que no solo es largo, sino que en ciertas ocasiones puede parecer tedioso, por lo que los encargados de realizar dicha tarea simplemente no lo hacen por lo que ello implica y de ahí no solo la desidia, sino el miedo que les puede producir acudir a una especie de «twilight zone».

\section{El Derecho uniforme y las calificaciones}

¿Se puede afirmar que la incorporación del Derecho uniforme en el ordenamiento jurídico conlleva que el procedimiento conocido como las calificaciones desaparezca al igual que el conflicto de leyes? En este caso creemos que no es así, toda vez que para aplicar el Derecho uniforme el juez debe interpretarlo y esta interpretación, en la mayoría de los casos, se llevará a cabo a la luz del propio Derecho interno, es decir, legi fori. Sin embargo, en muchas ocasiones, como señalamos anteriormente, la mayor parte de las normativas uniformes, en especial aquellas de carácter multilateral, pregonan por una interpretación del tipo lege causae, donde el fundamento esencial será que la interpretación se haga de acuerdo al Derecho a partir del cual se configuró la situación jurídica que debe ser resuelta, es decir, desde el propio Derecho uniforme y no desde Derecho interno como tal ${ }^{61}$.

ción deberá ser expresa o resultar de manera cierta de los términos del contrato o de las circunstancias del caso. Para esta elección, las partes podrán designar la ley aplicable a la totalidad o solamente a una parte del contrato». De igual manera, el art. 7. ${ }^{\circ}$ de la Convención Interamericana sobre el Derecho aplicable a los contratos internacionales.

${ }^{61}$ En la misma línea, Fernández Rozas afirma: «De ahí que, en la práctica, el remedio 
Por tanto, en ese caso estimamos que las calificaciones subsisten y ambas pueden aplicarse cuando se analiza y determina cierta figura jurídica que se hace necesaria para resolver un caso en particular.

\section{El Derecho uniforme y el conflicto de leyes}

Ahora nos preguntamos aquí: ¿que sucede en el caso de un conflicto de leyes en materia de Derecho internacional, esto es, cuando dos normas, una local y una extranjera, se presentan como adecuadas para regular una situación jurídica dada? En este caso, si el juez u operador jurídico no cuentan dentro de sus normas internas de Derecho internacional privado con una norma precisa que regule tal situación, entonces se deberá analizar cuál de estas presenta unos vínculos más estrechos con la situación en litigio. En el caso del Derecho uniforme tal incertidumbre puede desaparecer, ya que precisamente ese es uno de sus propósitos, esto es, acabar con los vacíos o lagunas que existen respecto a la aplicación de la norma que sea la más idónea. En este caso, estimamos que la afirmación con relación al desaparecimiento de los conflictos de leyes puede ser cierta, pero no en su totalidad, ya que el Derecho uniforme complementa, pero no resuelve de manera total, todos los litigios que se presentan con relación a una situación dada, es decir, con su implementación el riesgo de negación de justicia es menor, pero no desaparece de manera definitiva.

habitual consiste en el sometimiento de la cuestión interpretativa a la jurisdicción del Estado que aplica el Convenio. En este caso, es indudable que puede suscitarse un "conflicto de interpretaciones", toda vez que el ordenamiento del Estado con el cual también está conectada la relación jurídica controvertida puede tener un criterio divergente acerca de los términos del Convenio. Evidentemente, la interpretación fori es la que prevalece, lo cual puede frustrar la espiración uniforme del texto aplicado. Esta posición maximalista puede ser matizada por vía jurisprudencial a través de ciertos mecanismos que, en nuestra opinión, no pueden generalizarse. Concretamente, en los casos en que el Convenio de Derecho uniforme abarque aspectos de Derecho material y de Derecho aplicable, y la divergencia se centre en una institución de Derecho material, cabría la posibilidad, no sin proceder con antelación a un complejo proceso de elucubración teórica, de acudir a una norma de conflicto del Convenio para que esta designe el ordenamiento conforme al cual ha de realizarse la interpretación. Mas los problemas de interpretación no agotan los inconvenientes de la aplicación del Derecho uniforme en un Estado determinado. En efecto, no debe perderse de vista que existe una profunda interacción entre las normas unificadoras y el sistema interno donde se reciben, de suerte que en la aplicación de estas se pueden suscitar ciertas distorsiones. Acaso la más significativa derive de la calificación como "uniformes" de las normas contenidas en un Convenio concreto». Vid. J. C. FERNÁNDEZ ROZAS, «Consideraciones en torno a la relevancia del Derecho uniforme...», op. cit., p. 5228. 


\section{El Derecho uniforme y el forum shopping}

Otra de las cuestiones que generan ciertos interrogantes en el campo jurídico internacional es aquella de saber si con la unificación de las normas se reduce el riesgo de que la partes en un litigio acudan a una jurisdicción exterior diferente a la del foro para buscar una solución que se adapte mejor a sus deseos o intereses y no a lo que legalmente deberían acudir. La situación anterior se le conoce en el ámbito del Derecho internacional privado como forum shopping, esto es, la búsqueda por parte del demandante de un tribunal que le brinde con su decisión un mejor resultado que se adapte a sus intereses propios, evadiendo en muchas ocasiones los tribunales que serían generalmente competentes para definir el litigio que se presenta, incluso incurriendo en lo que también se conoce como el fraude a la ley ${ }^{62}$.

En este caso en particular creemos que el Derecho uniforme puede reducir significativamente el riesgo de forum shopping, ya que sería un sinsentido acudir a un tribunal que seguramente va a fallar en los mismos términos que lo haría el tribunal del foro del cual se huyó, por lo cual ello desalentaría sobre todo al demandante a que acudiese a otro tribunal o al menos le quedaría más difícil de encontrar uno que se adaptase a sus deseos e intereses, ya que si bien la tendencia unificadora en la materia no es muy prolífica en estos casos, poco a poco se desarrollan instrumentos que ayudan a que este tipo de situaciones vayan siendo menos frecuentes; para el caso en concreto existen ciertos convenios en materia de competencia judicial que le han dado solución a esta problemática ${ }^{63}$.

Por otro lado, se ha podido comprobar que el Derecho uniforme también reduce el riesgo de que se presente el fraude a la ley, ya que con dicho proceso cada vez se cierra más el círculo de la incertidumbre con relación a las normativas aplicables, por lo que el Derecho de un Estado será similar al de los otros que hayan adoptado el instrumento unificado. En este caso podemos ver cómo en el caso de normativas como la Convención de Viena sobre la Compraventa Internacional de Mercaderías (también conocida como CISG), donde las partes, de acuerdo a su art. $6^{\circ}$, excluyen su aplicación a la relación contractual que las une y designan el Derecho de un Estado que no hace parte del convenio (i. e., Venezue-

62 B. Audit, Droit International Privé, Paris, Economica, 2010, p. 46.

${ }_{63}$ Reglamento (UE) núm. 1215/2012 del Parlamento Europeo y del Consejo, de 12 de diciembre de 2012, relativo a la competencia judicial, el reconocimiento y la ejecución de resoluciones judiciales en materia civil y mercantil. 
la), puede presentarse el caso de que las normas de Derecho internacional privado de aquel Estado remitan al Derecho aplicable a la materia o a la costumbre internacional —en cuyo caso será la misma CISG_- por lo que el deseo de las partes de evadir la aplicación de esa normativa queda en vano, ya que indefectiblemente se les aplicará la misma independientemente del lugar donde se encuentren, puesto que en la mayoría de los Estados que no la han ratificado, la misma tiene aplicación vía sus normas internas de Derecho internacional privado.

\section{CONSIDERACIONES FINALES}

Primera. La cuestión de si existe o no un conflicto entre el Derecho uniforme y el Derecho interno de un determinado Estado (donde el primero ha sido incorporado) ha venido suscitando muchos interrogantes durante las últimas décadas, en especial con relación a cuál de ellos tiene prevalencia en cuanto a su aplicabilidad. Esto se da porque al momento de adjudicar una norma a un determinado problema jurídico puede presentarse cierto dilema para el operador jurídico encargado de darle solución al mismo, ya que es posible que tenga frente a sí dos normas que aparentemente pueden servir para tal propósito. En este caso, si la norma uniformizante aún no ha recibido una adecuada incorporación dentro de ese ordenamiento jurídico y este estima que es la correcta, puede recurrir a las soluciones que le brindan tanto el principio de specialia generalibus derogant ${ }^{64}$ como el de lex posterior priori derogat; ello teniendo en cuenta que su función principal será la de brindar la solución más justa posible y que cualquier antinomia entre las dos normas debe resolverse a favor del Derecho uniforme como ley especial.

Segunda. En cuanto a la aplicabilidad del Derecho uniforme, existe un gran problema y este depende esencialmente del nivel de conocimiento e idoneidad que tengan quienes son los encargados de incorporar normas uniformes en los ordenamientos jurídicos, especialmente por vía legislativa, ya que la facilidad con la que se incorpore dependerá del conocimiento que se tenga de aquella materia en especial. Se afirma esto porque no es lo mismo para un parlamentario holandés aprobar la incorporación de una normativa uniforme que para uno latinoamericano, asiático o africano,

${ }^{64}$ Un ejemplo de ello es el núm. 1 del art. 10 del Código Civil colombiano, que señala: «La disposición relativa a un asunto especial prefiere a la que tenga carácter general». 
que no está habituado a la materia y que tiene muchos recelos en cuanto a la utilización de una norma en la cual él no participó y poco le interesa el bienestar que aquella le pueda aportar a su comunidad, porque en muchos caos su orgullo «patrio» estará por delante del bienestar común.

Tercera. Con relación a la función de quienes deben aplicar la normativa uniforme (operadores jurídicos) existe también mucha reticencia y rechazo en cuanto a la utilización de aquella, ya que al no tener una preparación adecuada (la mayoría de las veces porque áreas como el Derecho internacional privado son desconocidas, infravaloradas o subutilizadas en muchos ordenamientos jurídicos —en especial el colombiano- y por el miedo a un eventual prevaricato) los jueces $\mathrm{u}$ otros funcionarios acuden directamente a su Derecho interno, incluso cuando alguna de las partes les haya puesto de relieve la particularidad e internacionalidad de la situación jurídica que deben fallar y el Derecho que deben aplicar.

Cuarta. Por tanto, la dualidad en cuanto a la aplicación del Derecho uniforme genera un gran problema el cual se presenta especialmente en el desconocimiento de la dinámica propia de esta clase de Derecho por parte no solo de legisladores, sino de operadores jurídicos, quienes quieren hacer parte o estar inmersos en una sociedad global pero, al mismo tiempo, desean que su comunidad se regule por sus propias normas interna, y eso en este caso no solo no es posible, sino que representa un riesgo para la seguridad jurídica tanto interna como global.

Quinta. Hablar ahora de una «guerra anunciada» no en el sentido literal del término puede tener cierta connotación, ya que en función del nivel de desarrollo del Estado (tanto en lo económico como en lo social, lo cultural y lo jurídico) dependerá la utilización armónica de las normativas uniformes con el Derecho interno. Aunque dicho proceso requiera un esfuerzo intelectual mayor, estimamos que, en este caso, los resultados valdrán la pena.

Igualmente hay que tener presente que en el proceso de elaboración del Derecho uniforme concurren verdaderos especialistas y estudiosos de la materia que será sometida a regulación, los cuales durante años unen esfuerzos para tratar de elaborar un trabajo de excelente calidad y fiabilidad. Sin embargo, no suele suceder lo mismo cuando se trata de un trabajo de la misma índole llevado a cabo por el órgano legislativo de ciertos Estados donde poco se conoce o se ha trabajado sobre la materia, lo que prevé de antemano un resultado bastante deficiente, por no decir «catastrófico», frente a la utilidad que pueda tener la aplicación de la nueva normativa elaborada por el legislador local. 
Sexta. Una eventual solución ante la reticencia de los Estados para adoptar e incorporar el Derecho uniforme en sus ordenamientos jurídicos - ya que no es un secreto que muchos funcionarios gubernamentales, con el argumento o ropaje de que se deben defender a ultranza las tradiciones y los particularismos legales de la sociedad, se oponen a ello, evitando a toda costa su implementación por cualquier medio- nos lleva a considerar una alternativa y es aquella de acudir a un cauce mucho más flexible, esto es, el de la ley modelo como explicitación del soft law, instrumento que suele ser adoptado en el seno de una conferencia internacional y que no tiene un carácter obligatorio directo, sino que su función es inspirar al legislador interno a la hora de codificar una determinada materia cubierta por dicha ley modelo ${ }^{65} \mathrm{o}$ de ayudar al funcionario judicial a encontrar una solución más acorde con la situación jurídica que debe resolver.

\section{BIBLIOGRAFÍA}

AdAme GodARD, J., Estudios sobre la compraventa internacional de mercaderías, México DF, Universidad Nacional Autónoma de México, 1991.

Audit, B., «Flux et reflux de la crise des conflits de lois», Travaux du comité français de Droit international privé. Journée du cinquantenaire. Problèmes actuels de méthode en droit international privé, Paris, Centre National de la Recherche Scientifique, 1988.

- Droit International Privé, Paris, Economica, 2010.

Ayala Martínez, J. M., «El Derecho natural antiguo y medieval», Revista Española de Filosofía Medieval, núm. 10 (2003), pp. 387-396, disponible en https://www. uco.es/filosofiamedieval/sites/default/files/revistas/vol10/refmvol10a35.pdf.

BAsEDow, J., «The Renascense of Uniform Law. European Contract Law and its components», Legal Studies, vol. 18, núm. 2 (1998), pp. 121-145.

Bonell, M. J., «International Uniform Law in Practice - Or Where the Real Trouble Begins», American Journal of Comparative Law, núm. 38 (1990), pp. 865-888, disponible en http://www.cisg.law.pace.edu/cisg/biblio/bonell2.html.

Boutros-GHALI, B., «Discours d'ouverture. Le Droit commercial uniforme au XXI siècle», en Actes du Congrès de la Commission des Nations Unies pour le droit commercial international, New York, Publication des Nations Unies, 1995.

Cabrillac, R., Las codificaciones, Santiago de Chile, Flandes indiano, 2009.

Conseil D'Etat, «L'influence internationale du Droit Français. La documentation française», Paris, 2001, disponible en http://www.ladocumentationfrancaise.fr/ var/storage/rapports-publics/014000702.pdf.

65 J. C. FERnÁNDEZ ROZAS, «Consideraciones en torno a la relevancia del Derecho uniforme...», op. cit., p. 5210. 
Contreras, F. J., «La idea del espíritu del pueblo en F. C. v. Savigny», Anales de la Cátedra Francisco Suárez, núm. 35 (2001), pp. 161-187, disponible en bttp:// www.artic.ua.es/biblioteca/u85/documentos/1794.pdf.

ENDERLEIn, F., Uniform Law and its Application by Judges and Arbitrators. International Uniform Law in Practice, Oxford, Oxford University Press, 1987, pp. 329 353, disponible en http://www.cisg.law.pace.edu/cisg/biblio/enderlein.pdf.

Fernández Baquero, M. E., «Historia y fuentes del Derecho romano», disponible en bttp://digibug.ugr.es/bitstream/10481/21703/1/HISTORIA\%20Y\%20 FUENTES\%20DEL\%20DERECHO\%20ROMANO.pdf.

FERnÁNDEZ DE BujáN, A., «Conceptos y dicotomías del ius», disponible en https:// repositorio.uam.es/bitstream/handle/10486/3131/14198_3RJ008.pdf? sequence $=1$.

Fernández Rozas, J. C., «Consideraciones en torno a la relevancia del Derecho uniforme en la regulación del tráfico privado externo», en J. L. IGLESIAS PRADA (coord.), Estudios jurídicos en homenaje al profesor Aurelio Menéndez, t. IV, Madrid, Civitas, 1996, pp. 5209-5238.

- «Los procesos de unificación internacional del Derecho privado: técnicas jurídicas y valoración de resultados», en J. M. GARCía Collantes (ed.), La unificación jurídica europea. Seminario organizado por el Consejo General del Notariado en la UIMP, Madrid, Civitas, 1999, pp. 17-44.

Foriers, P., «L'incidence des conventions internationales sur le Droit commercial», disponible en bttp://rbdi.bruylant.be/public/modele/rbdi/content/files/RBDI\%201966/RBDI\%201966-1/Informations/RBDI\%201966.1 por 10020-\%20pp. \%20278 por 10020 por $100 C 3$ por $100 A 0$ por 10020298 por 10020-\%20informations.pdf.

HerRera, D. A., «Ius Gentium, ¿Derecho natural o positivo?», disponible en bttps://fccuniversitario.files.wordpress.com/2012/06/herrera-ius-gentium-derecho-natural-o-derecho-positivo.pdf.

Kamde, I. F., «Harmonisation, unification et uniformisation. Plaidoyer pour un discours affiné sur les moyens d'intégration juridique», Revue de Droit Uniforme, vol. 13, núm. 3 (2008), pp. 709-745, disponible en bttps://www.unidroit. org/english/publications/review/contents/2008.pdf.

Kozuka, S., «The Economic Implication of Uniform Law», Revue de Droit Uniform, vol. 12, núm. 4 (2007), pp. 683-697, disponible en bttps://www.unidroit. org/english/publications/review/contents/2007.pdf.

Malintoppi, A., «Mesures tendant à prévenir les divergences dans l'interprétation des règles de Droit uniforme», Yearbook of the International Institute for the Unification of Private Law, 1959, pp. 249-275.

- «Les relations entre l'unification et I'harmonisation du droit et la technique de l'unification ou de l'armonisation par voie d'accords internationaux», Unification du Droit (1967-1968), pp. 43 y ss.

O'Honnold, J., Objectifs de l'unification. Le Droit commercial uniforme au XXI siècle. Actes du Congrès de la Commission des Nations Unies pour le Droit Commercial International, 1992, New York, Nations Unies, 1995, disponible 
en bttps://www.uncitral.org/pdf/french/texts/general/Uniform_Commercial_ Law_Congress_1992_f.pdf.

Paquette, M., «La mondialisation des règles de Droit: ¿coercition ou liberté?», XI Conference des Juristes de l'État, pp. 179-208, disponible en bttp://www. conferencedesjuristes.gouv.qc.ca/files/documents/8l/40/lamondialisationdesreglesdedroit.pdf.

Pereznieto Castro, L., «La revolución del Derecho internacional privado en el mundo de hoy», Anuario Hispano-Luso-Americano de Derecho Internacional, vol. 21 (2013), pp. 401-419.

Rigaux, F., «Codification of Private International Law: Pros and Cons», Louisiana Law Review, vol. 60, núm. 4 (2000), pp. 1321-1330.

- «Les incidences des conventions internationales en Droit interne», disponible en bttp://rbdi.bruylant.be/public/modele/rbdi/content/files/RBDI\%201966/ RBDI\%201966-1/Informations/RBDI\%201966.1 por 10020-\%20pp.\%20278 por 10020 por 100C3 por $100 A 0$ por 10020298 por 10020-\%20informations.pdf.

Savigny, F. C. von, Sistema de Derecho romano actual, edición de J. Mesía y M. Poley, vol. VIII, Alicante, Biblioteca Virtual Miguel de Cervantes, 2009.

Scotti, L. B., El rol de los organismos internacionales en la armonización del Derecho internacional privado, Buenos Aires, Centro Argentino de Estudios Internacionales, 2015, disponible en bttp://w1.cejamericas.org/index.php/ biblioteca/biblioteca-virtual/doc_view/6537-el-rol-de-los-organismos-internacionales-en-la-armonizaci\% C3 por 100B3n-del-derecho-internacional-privado.html.

Serge Kablan, A., «L'uniformisation régionale du droit: processus comparés et Projet de l'OHADA en transport routier», Mémoire présenté à la Faculté des études supérieures de l'université Lavai, disponible en bttp://www.collectionscanada.gc.ca/obj/s4/f2/dsk2/ftp03/MQ55591.pdf.

Snijders, H., y Vogenauer, S., Content and Meaning of National Law in the Context of Transnational Law [Interpretation of UNIDROIT Principles of International Commercials Contracts by national Courts], München, European Law Publishers, 2009.

SoleIL, S., «¿Le Code Civil de 1804 a-t-il été concu comme un modele juridique pour les nations?», disponible en http://fhi.rg.mpg.de/debatte/Code 20Civil/ pdf 20files/0503soleil.pdf.

Stephan, P. B., «The Futility of Unification and Harmonization in International Commercial Law», University of Virginia School of Law Legal Studies Working Papers Series, 1999, disponible en http://papers.ssrn.com/paper. taf?abstract_id=169209.

Tunc, A., «Standards juridiques et unification du Droit», Revue Internationale de Droit Comparé, vol. 22, núm. 2 (1970), pp. 247-261, disponible en bttp://www. persee.fr/docAsPDF/ridc_0035-337_1970_num_22_2_15698.pdf.

Zuleta Puceiro, E.,«Savigny y la teoría de la ciencia jurídica», Anuario de Filosofía del Derecho, núm. 19 (1976-1977), pp. 57-82, disponible en bttps://dialnet. unirioja.es/descarga/articulo/1985426.pdf. 